\section{Seroprevalence and Risk Factors associated with Helicobacter pylori Infection in Blood Donors in Salvador, Northeast-Brazil}

\begin{abstract}
Andre C. Lyra ${ }^{1}$, Genoile Santana ${ }^{1}$, Nelma Santana ${ }^{3}$, Anibal Silvany-Neto ${ }^{2}$, Emilia Magalhães ${ }^{1}$, Eduardo M. Pereira ${ }^{4}$, Ramiro Mascarenhas ${ }^{1}$, Marcos C. Lyra ${ }^{1}$, Andrea Veiga ${ }^{1}$, Karina Ferreira ${ }^{1}$, Schilioma Zaterka $^{5}$ and Luiz G. Lyra ${ }^{1}$
\end{abstract}

\author{
Gastroenterology and Hepatology Service of Federal \\ University of Bahia and Gastro-Hepatology Service of \\ São Rafel Hospital ${ }^{1}$, Departament of Epidemiology of \\ Federal University of Bahia ${ }^{2}$, Hemocentro of Bahia \\ $(\text { HEMOBA })^{3}$, Central Laboratory-LACEN ${ }^{4}$, Salvador, \\ BA; Discipline of Gastroenterology, Unicamp, SP, Brazil
}

\begin{abstract}
Helicobacter pylori plays an important role in the etiology of peptic ulcer disease. Its prevalence appears to be higher in developing countries. We evaluated the seroprevalence of $H$. pylori and risk factors associated with infection in voluntary blood donors who attended the main blood center of the city of Salvador, Brazil. The subjects responded to an epidemiological questionnaire, with information about sex, age, race, lifestyle, social-economic level indicators, and residence and hygiene conditions. Anti- $\mathrm{H}$. pylori antibody was determined by ELISA (Cobas Core, Roche). Three hundred and seven subjects were included in the study. Anti- $H$. pylori antibody results were indeterminate in 33 individuals $(10.8 \%)$, who were excluded from analysis. Among the remaining 274 subjects, 187 (68.2\%) were anti-H. pylori positive. Based on multivariate logistic regression analysis three variables were found to be significantly associated with a higher prevalence of $\mathrm{H}$.pylori infection: absence of plumbing in the residence during childhood, a history of rainwater invading the dwelling during childhood, and low ingestion of milk.

Key Words: $\boldsymbol{H}$. pylori, seroprevalence, risk factors, Brazil.
\end{abstract}

Helicobacter pylori plays a significant role in the etiology and pathogenesis of chronic active gastritis and peptic ulcer disease $[1,2,3]$. It is estimated that $50 \%$ of the world's population is infected by this bacteria $[4,5]$. The microorganism was first described in 1983 [6,7], but its epidemiology has not been entirely elucidated. Data regarding risk factors and modes of transmission are still controversial; it appears that there could be several modes of transmission $[8,9,10]$. In Brazil, peptic

Received on 20 August 2002; revised 10 October 2003. Address for correspondence: Dr..Andre C Lyra, MD, Serviço de Gastro-Hepatologia do Hospital São Rafael, Salvador-BA, Brasil. Rua Socrates Guanaes Gomes, 84, room 401, Salvador - Bahia - Brazil - Zip code: 40.283.320 Phone - Fax (55)-(71)452-9589. This study was supported in part by the CNPq.

The Brazilian Journal of Infectious Diseases 2003;7(5):339-345 (C) 2003 by The Brazilian Journal of Infectious Diseases and Contexto Publishing. All rights reserved. ulcer disease is an important cause of morbidity [11]. There are several studies about the epidemiology of $H$. pylori infection in the Brazilian population. Rocha et al. [12], using indirect immunofluorescence, detected a prevalence of $62.1 \% \mathrm{H}$. pylori infection in asymptomatic Brazilian blood donors in an urban area, this is a less specific test than the enzyme-linked immunosorbent assay (ELISA). Souto et al. [13] reported a prevalence of $84.7 \% \mathrm{H}$. pylori infection in adults in a rural area in a central region of Brazil, using ELISA. Further studies regarding the epidemiology of this bacterial infection in the Brazilian population should be encouraged in order to identify local risk factors. We evaluated the prevalence of $H$. pylori infection in voluntary blood donors of the city of Salvador in Northeast Brazil, utilizing an enzyme-linked immunosorbent assay (ELISA-COBAS CORE anti-H.pylori), and we identified possible risk factors. 


\section{Materials and Methods}

Subjects. We made a cross-sectional study of voluntary blood donors who attended the main blood center of Bahia (HEMOBA) and who accepted participation in the study during 1997 and 1999. Informed written consent was obtained from all subjects; the study was approved by the institutional review boards and the protocol conformed to the ethical guidelines of the 1975 Declaration of Helsinki.

Inclusion and exclusion criteria. We only included patients who were born and who lived in the city of Salvador, Bahia; they must have fulfilled the blood center criteria for blood donation, which included, among other requirements, being 18 to 60 -years-old. Patients who had lived in any city other than Salvador for any period of time were excluded from the study.

Variables analyzed. Subjects responded to an epidemiological questionnaire immediately before blood donation. The questionnaires were applied on weekdays in a random fashion. No apparent unusual situation in the blood center was detected during the period the interviews were done. The independent variables studied were: gender, race, weight, height, age (over or under 28), civil state (married / living together, or single), alcohol and coffee consumption, smoking, type and frequency of food ingested (beef, lamb, poultry, fish, pork, vegetables, fruits, milk), type of water ingested during childhood and adulthood (filtered / boiled, or not), garbage collection in the neighborhood during childhood and adulthood, indicators of socialeconomic status: educational level (complete high school or higher level; incomplete high school or lower level), family income (over or less than 5 minimum salaries), neighborhood (wealthy or not), type of dwelling (shack or house / apartment), water supply (presence or absence of plumbing), sewage system, number of rooms and number of persons residing in each dwelling, history of rainwater invading or not the dwelling (the latter four items were asked regarding childhood and present time). No main independent variable was specified due to the exploratory nature of the study. Helicobacter pylori infection was considered the dependent variable.

ELISA for H. pylori. At the time of venous puncture for donation a 10-ml blood sample was drawn and the sera were stored at $-20^{\circ} \mathrm{C}$. The ELISA for $\mathrm{H}$. pylori was performed after all questionnaires were given. The period between the time the first serum was stored and the ELISA tests was 14 months. AntiH.pylori antibodies were assayed by the Cobas Core anti-H. pylori IgGEIA (Roche Diagnostics Division, Basel-Switzerland), a second generation EIA. The test was performed essentially according to manufacturer's instructions. This method has been previously validated in the Brazilian population. The sensitivity, specificity and positive and negative predictive values of the test are 95.4, 100, 100 and $91.4 \%$, respectively [14]. Indeterminate results were excluded from analysis.

Statistical analysis. The sample size was obtained as previously described [15]. We considered an $\mathrm{N}$ of 45,000 (estimated number of donors in one year), an absolute precision of $5.5 \%$, a confidence level of $95 \%$, and an estimated prevalence of $H$. pylori infection of $68.2 \%$. This prevalence was obtained retrospectively at the end of the study. Using these parameters, the required sample size should be 274 donors. The chisquare test was used to compare discrete variables; continuous variables were expressed as mean \pm SEM and were analyzed by a non-paired two-tailed t-test with a significance level of 5\%. Levenes' test was used to assess variance homogeneity. A multiple logistic regression analysis was carried out in an exploratory sense in order to adequately identify important independent variables. Prevalence ratios of infection were used as measures of association during the simple analysis, and odds ratios of infection in the logistic regression analysis, given the elevated frequency of the H. pylori infection in the population. Interaction terms were not taken into account. Variables were selected using the backward stepwise method and the statistical inference was based on likelihood ratio tests. The criterium utilized for variable exclusion was a $\mathrm{P}$ value 
greater than or equal to 0.17 . All the categorical independent variables were coded using an indicator variable scheme. The regression considered comparisons of predicted with observed outcomes, the likelihood of the observed results, the goodness-of-fit statistic and a residual analysis. Confidence intervals for odds ratios were calculated. All these statistics were done using the SPSS software (SPSS version 9.0, SPSS Inc. Chicago, IL).

\section{Results}

Three hundred and seven blood donors were included in the study. Detection of anti-H. pylori antibody was indeterminate in 33 subjects $(10.8 \%)$. These cases were excluded from analysis. Comparison between this group and the remaining 274 cases showed significant differences for three variables (Table 1). Among the remaining 274 blood donors, 54 (19.7\%) were female and $220(80.3 \%)$ were male. The mean age was $29 \pm 8.4$ years. Fifty one percent were single. Only 112 donors $(40.8 \%)$ had completed high school. Sixty three percent had an income between one and five minimum salaries, and $89 \%$ received up to 12 minimum salaries. The mean number of people residing in a dwelling during childhood was 7.5. The prevalence of anti-H. pylori in this population was $68.2 \%$. The prevalence of the antibody in the male group was $71.4 \%$ and in the female group it was $55.6 \%$ (Table 2). Based on bivariate simple analysis the variables that were significantly associated with the $H$. pylori infection are displayed in Table 3. There was no significant association with race, age, weight, height, civil state, alcohol and coffee consumption, smoking, educational level, family income, garbage collection in the neighborhood during childhood and adulthood, neighborhood, number of rooms and number of persons residing in each dwelling during childhood or at the present time, or water supply and sewage system at the present time.

In the multivariate analysis four variables were significantly associated with $H$. pylori infection at the $5 \%$ level: absence of plumbing in the residence during childhood, history of rainwater invading the dwelling during childhood, low ingestion of milk and high consumption of fish. The variables beef consumption, civil status, current type of dwelling and vegetable consumption showed borderline $\mathrm{P}$ values (considering $\propto=5 \%$ ) and were not discarded as unimportant (Table 4). Only three variables were significantly associated with a higher prevalence of $H$. pylori infection in both bivariate and multivariate analysis: absence of plumbing in the residence during childhood, history of rainwater invading the dwelling during childhood, and low ingestion of milk.

\section{Discussion}

In studying the prevalence of $H$. pylori infection we found that $68 \%$ of the subjects were $H$. pylori seropositive by ELISA. The study population consisted of blood donors and thus it does not necessarily correspond to the entire population of the city of Salvador, Bahia. However, the results are in accordance with previous studies that show a high seroprevalence of $H$. pylori infection in Brazilian populations $[12,13]$.

We did not find an association between $H$. pylori infection and educational level, family income or age. Nevertheless, it is important to note that most of the subjects who were enrolled had a low educational level and a low income, and this might have influenced the results. The population also mostly consisted of young adults, with few donors being 50 years-old or over, and $80 \%$ of the subjects were male; therefore, this study may not be ideal for an analysis of the whole population. Zaterka et al. found that $70 \%$ of the children of lowincome families in Brazil are already infected with $H$. pylori when they are 5 years old [16].

Three variables appeared to be risk factors for $H$. pylori infection in both bivariate simple analysis and multivariate analysis: history of rainwater invading the dwelling during childhood, absence of plumbing water system at the residence during childhood, and low ingestion of milk. To our knowledge, this is the first study to suggest rainwater infiltration as a potential source of $H$. pylori infection. This seems to be a plausible source of infection in developing countries, 
Table 1. Comparison between the group of 33 blood donors excluded from analysis and the remaining 274 blood donors

\begin{tabular}{|c|c|c|c|c|}
\hline Variable & Included cases & $\begin{array}{l}\text { Excluded cases } \\
\text { N }(\%)\end{array}$ & $\begin{array}{c}\mathbf{X}^{2} \\
\mathbf{N}(\%)\end{array}$ & Pvalue \\
\hline \multicolumn{5}{|l|}{ Educational level } \\
\hline $\begin{array}{l}\text { Complete high school } \\
\text { or higher educational level }\end{array}$ & $112(40.9)$ & $24(72.7)$ & 10.8 & 0.001 \\
\hline $\begin{array}{l}\text { Incomplete high school or } \\
\text { lower educational level }\end{array}$ & $162(59.1)$ & $9(27.3)$ & & \\
\hline \multicolumn{5}{|l|}{$\begin{array}{l}\text { Garbage collection in the } \\
\text { neighborhood at childhood }\end{array}$} \\
\hline Yes & $135(52.7)$ & $25(75.8)$ & 5.4 & 0.02 \\
\hline No & $121(47.3)$ & $8(24.2)$ & & \\
\hline \multicolumn{5}{|c|}{ Type of water ingested at adulthood } \\
\hline Filtered or boiled & $187(68.2)$ & $31(93.9)$ & 8.2 & 0.004 \\
\hline Not filtered or boiled & $87(31.8)$ & $2(6.1)$ & & \\
\hline
\end{tabular}

Table 2. Prevalence of anti-H.Pylori antibody in 274 blood donors according to gender

\begin{tabular}{lcccc}
\hline Gender & \multicolumn{2}{c}{ Anti-H.pylori } & & \\
\cline { 2 - 3 } & Positive & Negative & Prevalence ratio & 95\% Confidence interval \\
\hline Male & $157(71.4 \%)$ & $63(28.6 \%)$ & & \\
& & & 1.28 & \\
Female & $30(55.6 \%)$ & $24(44.4 \%)$ & & \\
Total & $187(68.2 \%)$ & $87(31.8 \%)$ & & \\
\hline
\end{tabular}

$\mathrm{X}^{2}=4.3 \mathrm{P}=0.038 . \mathrm{PR}=$ Prevalence ratio.

such as Brazil, since some neighborhoods may be subject to flooding during heavy rain and this favors the contact between the residents and the material originated from the surrounding sewer system. The association with absence of plumbing in the residence also suggests that $H$. pylori contamination and transmission could occur through water. Water has been considered a possible transmission route of $H$. pylori infection, especially in developing countries [17]. Swimming in rivers, streams, or pools increases the odds of infection, as does using streams as a drinking water source.

In a population-based study that evaluated children from Peru, water supply was an important source of
H. pylori infection in families with high or low social economic levels [18]. The fact the these conditions occurred during childhood is in accordance with previous studies that showed a greater probability of acquiring the infection during childhood; this could be a result of hygiene habits and a higher susceptibility to $H$. pylori infection during this period of life $[19,20]$.

In contrast to a previous study that did not find any association between high or low ingestion of milk and $H$. pylori infection, we found that low milk ingestion was a risk factor for $H$. pylori infection [21]. We also found that alcohol consumption and smoking were not important risk factors; this is in agreement with previous studies. Nevertheless this issue remains controversial [22-25]. 
Table 3. Distribution of dichotomized variables that were significant based on bivariate analysis $(n=274)$

\begin{tabular}{|c|c|c|c|c|c|}
\hline \multirow[b]{2}{*}{ Risk factor } & \multirow[b]{2}{*}{$\mathbf{N}$} & \multicolumn{2}{|c|}{ Anti-H. pylori antibody } & \multirow{2}{*}{$\begin{array}{c}\text { Prevalence ratio } \\
95 \%\end{array}$} & \multirow{2}{*}{$\begin{array}{c}\text { Confidence } \\
\text { interval }\end{array}$} \\
\hline & & Positive & Negative & & \\
\hline $\begin{array}{l}\text { Rainwater invading } \\
\text { dwelling in childhood }\end{array}$ & 270 & & & & \\
\hline Yes & & $56(83.6)$ & $11(16.4)$ & 1.32 & $(1.13 ; 1.53)$ \\
\hline No & & $129(63.5)$ & $74(36.5)$ & & \\
\hline Poultry consumption & 274 & & & & \\
\hline Yes & & $46(55.4)$ & $37(44.6)$ & 1.33 & $(1.08 ; 1.64)$ \\
\hline No & & $141(73.8)$ & $50(26.2)$ & & \\
\hline $\begin{array}{l}\text { Presence of plumbing } \\
\text { water system in childhood }\end{array}$ & 266 & & & & \\
\hline No & & $31(83.8)$ & $6(16.2)$ & 1.28 & $(1.08 ; 1.52)$ \\
\hline Yes & & $150(65.5)$ & $79(35.5)$ & & \\
\hline $\begin{array}{l}\text { Sewage system at } \\
\text { childhood }\end{array}$ & 263 & & & & \\
\hline No & & $47(82.5)$ & $10(17.5)$ & 1.27 & $(1.08 ; 1.48)$ \\
\hline Yes & & $134(65.0)$ & $72(35.0)$ & & \\
\hline $\begin{array}{l}\text { Type of water ingested } \\
\text { at adulthood }\end{array}$ & 274 & & & & \\
\hline Not filtered nor boiled & & $68(78.2)$ & $19(21.8)$ & 1.23 & $(1.05 ; 1.43)$ \\
\hline Filtered or boiled & & $119(63.9)$ & $68(36.4)$ & & \\
\hline Fruit consumption & 274 & & & & \\
\hline At least once a week & & $142(65.1)$ & $76(34.9)$ & 0.81 & $(0.69 ; 0.95)$ \\
\hline Less than once a week & & $45(80.4)$ & $11(19.6)$ & & \\
\hline Milk ingestion & 272 & & & & \\
\hline At least once a week & & $157(65.7)$ & $82(34.3)$ & 0.74 & $(0.64 ; 0.87)$ \\
\hline Less than once a week & & $29(87.9)$ & $4(12.1)$ & & \\
\hline Vegetable consumption & 274 & & & & \\
\hline At least once a week & & $132(63.8)$ & $75(36.2)$ & 0.78 & $(0.67 ; 0.90)$ \\
\hline Less than once a week & & $55(82.1)$ & $12(17.9)$ & & \\
\hline
\end{tabular}

Finally, we initially included 307 patients in the study, however 33 cases had indeterminate $H$. pylori serology results, and thus were excluded from analysis. Although we have found significant differences in three variables between this group and the remaining 274 cases, we believe that the number of excluded cases is probably too low to have influenced the results. Moreover, only two of these variables were previously reported to be associated with $H$. pylori infection. Most probably, the only possible consequences are an underestimate of prevalence ratios of these variables.

In summary, this study evaluated the seroprevalence of $H$. pylori in a population of blood donors from the city of Salvador in Northeast-Brazil and suggests possible risk factors for $H$. pylori infection in a developing country. Further large scale population-based studies are needed to better determine the role of these potential sources of transmission of $H$. pylori. 
Table 4. Risk factors for H. pylori infection: results of the multivariate analysis

\section{Covariable}

$\beta \quad$ SE $\quad \begin{gathered}\text { Likelihood ratio } \\ \text { Test-P-value }\end{gathered}$

Odds Ratio

CI (95\%)

\section{Rainwater invading dwelling in childhood}

Yes vs. no

\section{Beef consumption}

Yes vs. no

$0.9989 \quad 0.3986$

0.0081

2.7152

$(1.24 ; 5.95)$

Plumbing water system

$0.5700 \quad 0.3377$

0.0919

1.7682

$(0.91 ; 3.12)$

\section{in childhood}

No vs. yes

$1.0661 \quad 0.5097$

0.0251

2.9040

$(1.06 ; 7.88)$

\section{Civil state}

Other vs single

$-0.5543 \quad 0.3039$

0.0663

0.5745

$(0.31 ; 1.04)$

Milk ingestion

At least once a week vs.

$-1.8832 \quad 0.7625$

0.0023

0.1521

$(0.03 ; 0.67)$

less than once a week

\section{Fish consumption}

Yes vs. no

\section{Current type of dwelling}

House vs. apartment

\subsection{0}

0.3063

0.0042

2.3703

$(1.30 ; 4.32)$

\section{Vegetable Consumption}

Daily or weekly consumption vs. $\quad-0.6970$

0.6426

0.3714

0.0844

1.9015

$(0.91 ; 3.93)$

no or biweekly consumption

$\begin{array}{llll}0.3926 & 0.0667 & 0.4981 & (0.23 ; 1.07)\end{array}$

consumption consumption

\section{Constant}

\section{$1.6734 \quad 0.9172$}

$0.0681^{\mathrm{a}}$

a - Wald's statistic; CI: confidence interval.

\section{Acknowledgements}

This study was supported in part by the Conselho Nacional de Desenvolvimento Científico e Tecnológico (CNPq).

\section{References}

1. Tytgat G.N.J. Treatment of peptic ulcer. Digestion 1993;59:446-52.

2. Moss S.F., Fendrick A.M., Cave D.R., Modlin I.M. Helicobacter pylori - More light, less heat. Am J Gastroenterol 1998;93:306-10.

3. Peek Jr. R.M., Blaser M.J. Pathophysiology of Helicobacter pylori-induced gastritis and peptic ulcer disease. Am J Med 1997;102:200-7.
4. Megraud F., Brassens-Rabbe M.P., Denis F. Seroepidemiology of Campylobacter pylori infection in various populations. J Clin Microbiol 1989;27:1870-3.

5. Perez-Perez G.I., Dwarkin B.M., Chados J.E., Blaser M.J. Campylobacter pylori antibodies in humans. Ann Int Medicine 1988;109:11-7.

6. Warren J.R. Unidentified curved bacilli in the stomach of patients with gastritis and peptic ulceration. Lancet 1983; $1: 1273$.

7. Marshall B.J. Unidentified curved bacilli in the stomach of patients with gastritis and peptic ulceration. Lancet 1983;1:1273-4.

8. Hopkins R.J., Vial P.A., Ferreccio C., et al. Seroprevalence of Helicobacter pylori in Chile: Vegetables may serve as one route of transmission. J Infect Dis 1993;168:222-6.

9. Mégraud F. Transmission of Helicobacter pylori: Faecaloral versus oral-oral route. Aliment Pharmacol Ther 1995; 9(suppl.2):85-91. 
10. Rouland M. Transmission of Helicobacter pylori: Is it all child's play? Lancet 2000;55:332-3.

11. Oliveira L.C.M., Buso A.G., Siqueira F. ${ }^{\circ}$ L., et al. Peptic disease and Helicobacter pylori are highly prevalent in patients with the indeterminate form of Chagas disease: Report of 21 cases. Revista do Instituto de Medicina Tropical de São Paulo 1997;39:209-12.

12. Rocha G.A., Queiroz D.M.M., Mendes E.N., et al. Indirect immunofluorescence determination of the frequency of anti-H. pylori antibodies in Brazilian blood donors Braz J Med Biol Res 1992;25:683-9.

13. Souto F.J.D., Fontes C.J.F., Rocha G.A., et al. Prevalence of Helicobacter pylori infection in a rural area of the State of Mato Grosso, Brazil. Mem Inst Oswaldo Cruz 1998;93:171-4.

14. Rocha G.A., Oliveira A.M., Queiroz D.M., et al. Serodiagnosis of Helicobacter pylori infection by Cobas Core ELISA in adults from Minas Gerais, Brazil. Braz J Med Biol Res 1998;31:1263-8.

15. Daniel W.W. Biostatistics: A foundation for analysis in the health sciences, 1999; $7^{\text {th }}$ ed - John Wiley \&“Sons, New York.

16. Zaterka S., Nishimura N.F., Parente J.M., Libanês L. Prevalence of Helicobacter pylori infection in children population in Brazil. Gut 2002;51(Suppl III): A93.

17. Suerbaum S., Michetti P. Helicobacter pylori infection. N Engl J Med 2002;347:1175-86.

18. Klein P.D., Graham D. Y., Gaillour A., et al. Water source as risk factor for Helicobacter pylori infection in Peruvian children. Lancet 1991;337:1503-6.

19. Neale K.R., Logan R.P.H. The epidemiology and transmission of Helicobacter pylori infection in children. Aliment Pharmacol Ther 1995;9 (suppl.2):77-84.

20. Oliveira A.M.R., Queiroz D.M.M., Rocha G.A., Mendes E.N. Seroprevalence of Helicobacter pylori infection in children of low socioeconomic level in Belo Horizonte, Brazil. Am J Gastroenterol 1994;89:2201-4.

21. Begue R.E., Gonzalez J.L., Correa-Garcian H., Tang S.C. Dietary risk factors associated with the transmission of Helicobacter pylori in Lima, Peru. Am J Trop Med Hyg 1998;59:637-40.

22. Ogihara A., Kikuchi S., Hasegawa A., et al. Relationship between Helicobacter pylori infection and smoking and drinking habits. J Gastroenterol Hepatol 2000; 15:271-6.

23. Everhart J.E., Kruszon-Moran D., Perez-Perez G.I., et al. Seroprevalence and ethnic differences in Helicobacter pylori infection among adults in the United States. J Infect Dis 2000; 181:1359-63.

24. Woodward M., Morrison C., McColl K. An investigation into factors associated with Helicobacter pylori infection. J Clin Epidemiol 2000;53:175-81.
25. Giannuzzi F., Giannuzzi U., Bianciardi L., et al. Risk factors for acquiring Helicobacter pylori infection in a group of Tuscan teenagers. New Microbiol 2001;24:165-70. 